\title{
Utilization of an ANFIS-STSM Algorithm to Minimize Total Harmonic Distortion
}

\author{
Habib Benbouhenni \\ * Laboratoire d'Automatique et d'Analyse des Systèmes (LAAS), Departement de Génie Electrique, Ecole Nationale \\ Polytechnique d'Oran Maurice Audin, Oran, Algeria. \\ (habib0264@gmail.com )
}

¥Corresponding Author; Habib Benbouhenni, BP: 50B Ouled Fares Chlef Algeria, Tel: +213663956329,

habib0264@gmail.com

Received: 07.02.2020 Accepted:28.03.2020

\begin{abstract}
Recently applications of second order super-twisting sliding mode (STSM) algorithm become more convenient in control of AC machines. The conventional technique, the capability of creating a high value of current or voltage. On the other hand, the STSMC algorithm popular in more applications. There are several types of intelligent techniques such as neural networks (NNs), adaptive network-based fuzzy inference system (ANFIS) and fuzzy logic controller (FLC). The ANFIS controller is very popular than other controllers because its control is very simple in comparison with others. The new technique of STSMC is utilized to reduce the harmonic distortion in direct torque control (DTC). Cat ANFIS-STSM algorithm is introduced as a new STSM algorithm to minimize harmonic distortion and electromagnetic torque ripples. The simulation results have been carried out using Matlab/Simulink software.
\end{abstract}

Keywords: ANN, FLC, ANFIS, STSM, DFIG, THD, DTC, ANFIS-STSM.

$\begin{array}{ll}\text { Nomenclature } \\ \text { DFIG } & \text { Doubly fed induction generator } \\ \text { VSS } & \text { Variable structure systems } \\ \text { DTC } & \text { Direct torque control } \\ \text { DPC } & \text { Direct power control } \\ \text { SMC } & \text { Sliding mode controller } \\ \text { WPS } & \text { Wind power system } \\ \text { STSMC } & \text { Super-twisting sliding mode controller } \\ \text { PI } & \text { Proportional integral } \\ \text { ANN } & \text { Artificial neural network } \\ \text { ANFIS } & \text { Adaptive network-based fuzzy inference system } \\ \text { FL } & \text { Fuzzy logic } \\ \text { SVPWM } & \text { Space vector pulse width modulation } \\ \text { SOSMC } & \text { Second order sliding mode controller } \\ \text { THD } & \text { Total harmonic distortion }\end{array}$

\section{Introduction}

The development of variable structure systems (VSS) theories allows us to use the sliding mode controller (SMC) instead of traditional control schemes. The major advantages of the SMC technique are as follows: robust control and insensitivity to parameter variations [1]. On the other hand, several papers have been published based on SMC of doubly fed induction generator (DFIG) based wind power system (WPS) [2-7].

İn [8], direct power control (DPC) strategy based on artificial neural networks (ANN) algorithm is presented. İn [9], a twelve sectors DPC strategy was proposed based on the ANN algorithm, where the switching table is replaced with the ANN algorithm. İn [10], direct torque control (DTC) technique based on neural PI regulators and space vector pulse width modulation is presented. Neural networks and SMC are combined to control the DFIG-based wind turbines (DFIG-WT) [11]. İn [12], a modified SMC method was proposed based on the fuzzy logic (FL) technique, where the harmonic distortion of stator current is reduced compared to vector control. SMC and adaptive network-based fuzzy inference system (ANFIS) are combined to reduce the power ripple of DFIG-WT [13]. İn [14], second-order sliding mode controller (SOSMC) based on neural algorithm has been proposed. A fuzzy SOSMC method is designed to control the active/reactive power of DFIG-WT [15]. In [16], the ANFISSOSMC method is proposed to reduce the power ripple and electromagnetic torque of DFIG-WT. 
The robust technique used in this work is the second-order super-twisting sliding mode (STSM) algorithm with is a particular mode of SMC strategy.

In this work, the direct torque control (DTC) system with the application of the adaptive network-based fuzzy inference system (ANFIS) second-order super twisting sliding mode algorithms (ANFIS-STSMC) has been considered. The original contribution of this work is the application of the ANFIS-STSM algorithms in the DTC method of the DFIG and simulation investigation of this novel method.

This work is divided into 7 sections. In section 1 , the introduction is presented. In section 2, the mathematical model of the three-phase DFIG is described. The space vector pulse width modulation (SVPWM) strategy has been discussed in section 3. In section 4, the description of the ANFIS-STSM algorithm is presented. Section 5 deals with the description of the DTC technique with the application of ANFIS-STSMC algorithms. Simulation studies are presented and discussed in section 6 . The work is concluded with a summary.

\section{Mathematical model of three-phase DFIG}

The mathematical model of three-phase DFIG has been formulated based on commonly used simplifying assumptions presented in detail in [17-19].

The voltage equations of the rotor and stator in the basic $d-q$ coordinate system which rotates relatives to the stator at arbitrary angular speed wr :

$\left\{\begin{array}{l}V_{d s}=R_{s} I_{d s}+\frac{d}{d t} \psi_{d s}-\omega_{s} \psi_{q s} \\ V_{q s}=R_{s} I_{q s}+\frac{d}{d t} \psi_{q s}+\omega_{s} \psi_{d s}\end{array}\right.$

$\left\{\begin{array}{l}V_{d r}=R_{r} I_{d r}+\frac{d}{d t} \psi_{d r}-\omega_{r} \psi_{q r} \\ V_{q r}=R_{r} I_{q r}+\frac{d}{d t} \psi_{q r}+\omega_{r} \psi_{d r}\end{array}\right.$

Rotor flux components :

$\left\{\begin{array}{l}\psi_{d r}=L_{r} I_{d r}+M I_{d r} \\ \psi_{q r}=L_{r} I_{q r}+M I_{q r}\end{array}\right.$

And stator flux components :

$\left\{\begin{array}{l}\psi_{d s}=L_{s} I_{d s}+M I_{d r} \\ \psi_{q s}=L_{s} I_{q s}+M I_{q r}\end{array}\right.$

The equation of the electromagnetic torque (Te) :

$T_{e}=-\frac{3}{2} p \frac{M}{L_{s}} I_{q r} \cdot \psi_{d s}$
Where : $p$ is the number of pole pairs.

$\mathrm{T}_{\mathrm{e}}$ is the electromagnetic torque

The mechanical motion equation :

$T_{e}-T_{r}=J \cdot \frac{d \Omega}{d t}+f \cdot \Omega$

Where : $\Omega$ is the mechanical rotor speed.

$J$ is the inertia

$f$ is the viscous friction coefficient

$T_{r}$ is the load torque.

\section{Three-level SVPWM technique}

In the analyzed conventional DTC method, it is assumed that three-phase DFIG is controlled by a 2-level three-phase voltage source inverter (VSI). Voltage space vectors generated by the three-phase VSI in the coordinate system $\alpha$ $\beta$ are shown in Figure 1.

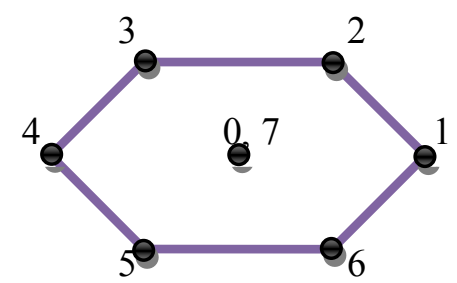

Figure 1. Voltage space vectors generated by three-phase VSI in the coordinate system $(\alpha-\beta)$.

For three-phase VSI, as shown in Figure 1, there are total 8 vectors : 6 active vectors $(1,2,3,4,5,6)$ and two zero vectors $(0,7)$ in $\alpha-\beta$ coordinate system.

The traditional DTC method gives more ripples in rotor flux and electromagnetic torque [20]. In [21], the THD of stator current is a $0.95 \%$ and $1.31 \%$ in [22].

In this method, the active and reactive powers of DFIG are controlled by two proportional-integral (PI) controllers and a conventional SVPWM technique (See Figure 4). This method is easy to implement and simple structure compared to the DTC method based on the switching table (ST). The DTC with PI controllers reduces the rotor flux and electromagnetic torque ripples compared to the DTC with traditional ST [23].

For the three-level SVPWM technique, as shown in Figure 2, there are a totally 6 hysteresis comparators and two portoses. This proposed modulation use of maximum (MAX) and minimum (MIN) of three-phase voltages $(\mathrm{Va}, \mathrm{Vb}, \mathrm{Vc})$. This modulation strategy is detailed in [24-27]. The graphical representation of the hysteresis comparators of the SVPWM technique is shown in Figure 3. 
Where:

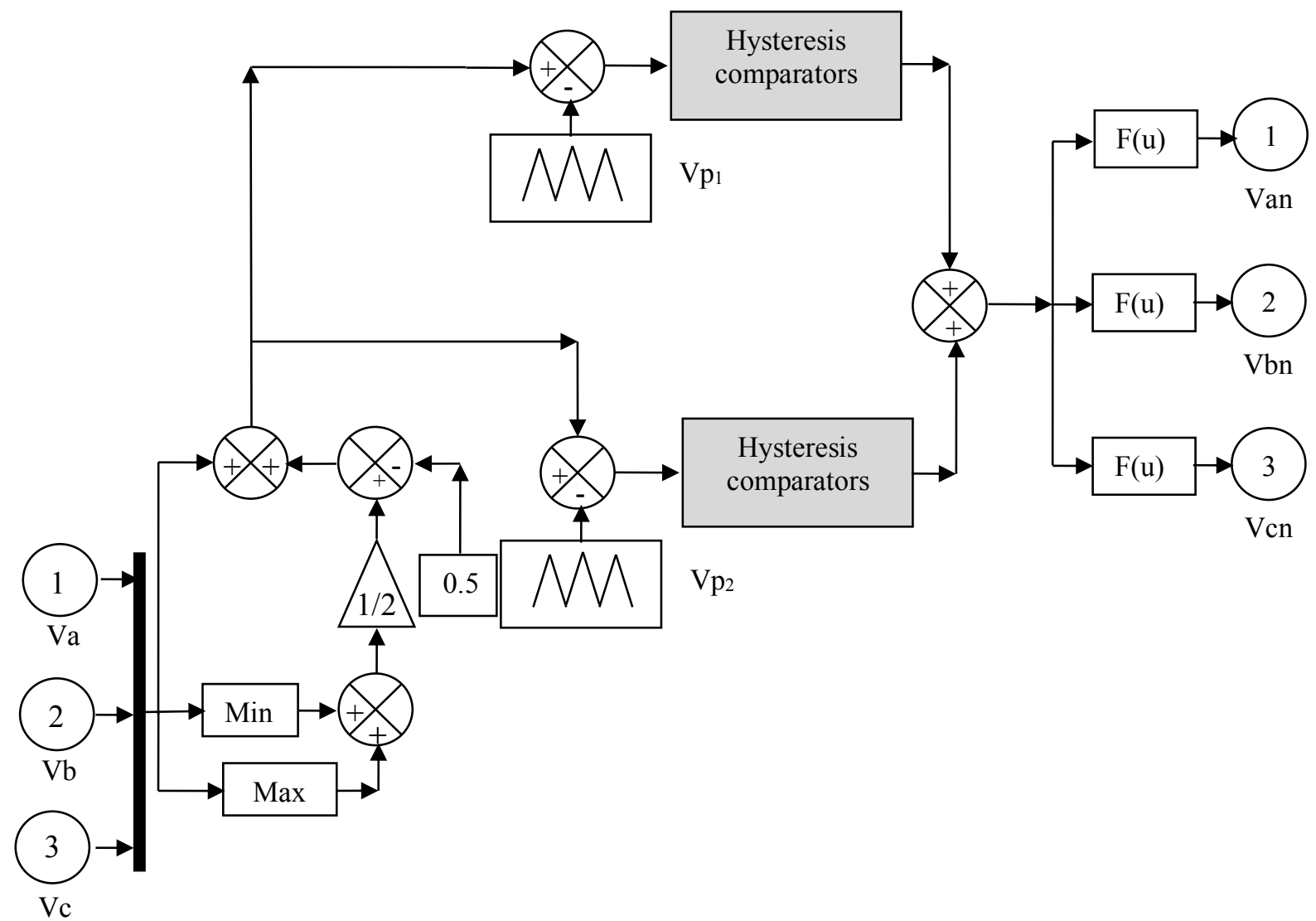

Figure 2. Three-level SVPWM strategy.

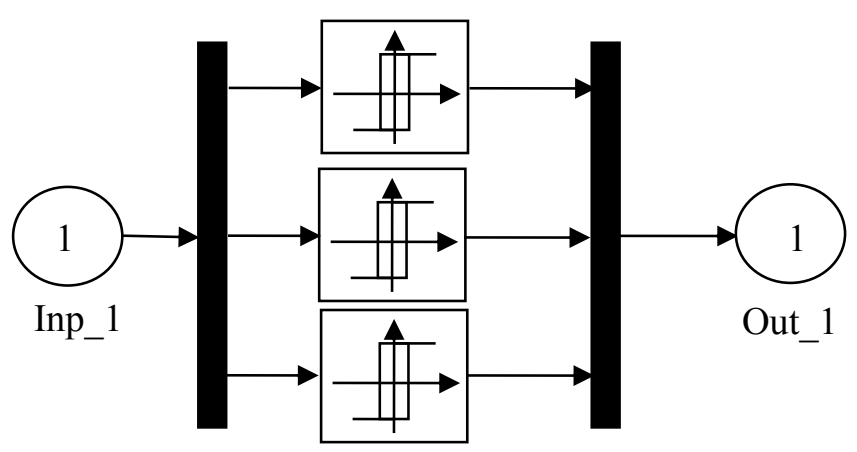

Figure 3. Block diagram of hysteresis comparators.

The magnitude of rotor flux, which can be estimated by:

$\left\{\begin{array}{l}\Psi_{r \alpha}=\int_{0}^{t}\left(v_{r \alpha}-R_{r} i_{r \alpha}\right) d t \\ \Psi_{r \beta}=\int_{0}^{t}\left(v_{r \beta}-R_{r} i_{r \beta}\right) d t\end{array}\right.$

The rotor flux amplitude is given by:

$\Psi_{r}=\sqrt{\Psi_{r \alpha}^{2}+\Psi_{r \beta}^{2}}$

$$
\left|\overline{\Psi_{r}}\right|=\frac{\left|\overline{V_{r}}\right|}{w_{r}}
$$

The rotor flux angle is calculated by :

$$
\theta_{r}=\operatorname{arctg}\left(\frac{\Psi_{r \beta}}{\Psi_{r \alpha}}\right)
$$




\section{Description of the ANFIS-STSM algorithm}

The STSM algorithm maintains the advantages of the traditional SMC strategies and allows for the elimination of the undesirable phenomena of chattering [28]. This method of command is easy to implement and simple algorithm compared to other technique (fuzzy logique or neural networks). This technique no need to model mathematical of system. On the other hand, the output signal from regulator of this type is comparable with the control signal obtained form linear proportional-integral (PI) controllers. This technique is detailed in [29]. The control law of the STSM algorithms can be defined as follows : equations of the output signals. These equations in the matrix from are presented as follows [30]:

$$
\left\{\begin{array}{c}
u=K_{p} \cdot|S|^{r} \operatorname{sgn}(S)+u_{1} \\
\frac{d u_{1}}{d t}=K_{i} \cdot \operatorname{sgn}(S)
\end{array}\right.
$$

Where $\mathrm{S}$ is the switching function determined for the STSM algorithm, $\mathrm{Kp}$ and $\mathrm{Ki}$ are the coefficients of the proportional and integral parts of the STSM algorithm, respectively; $r$ is the exponent defined for the STSM algorithm.

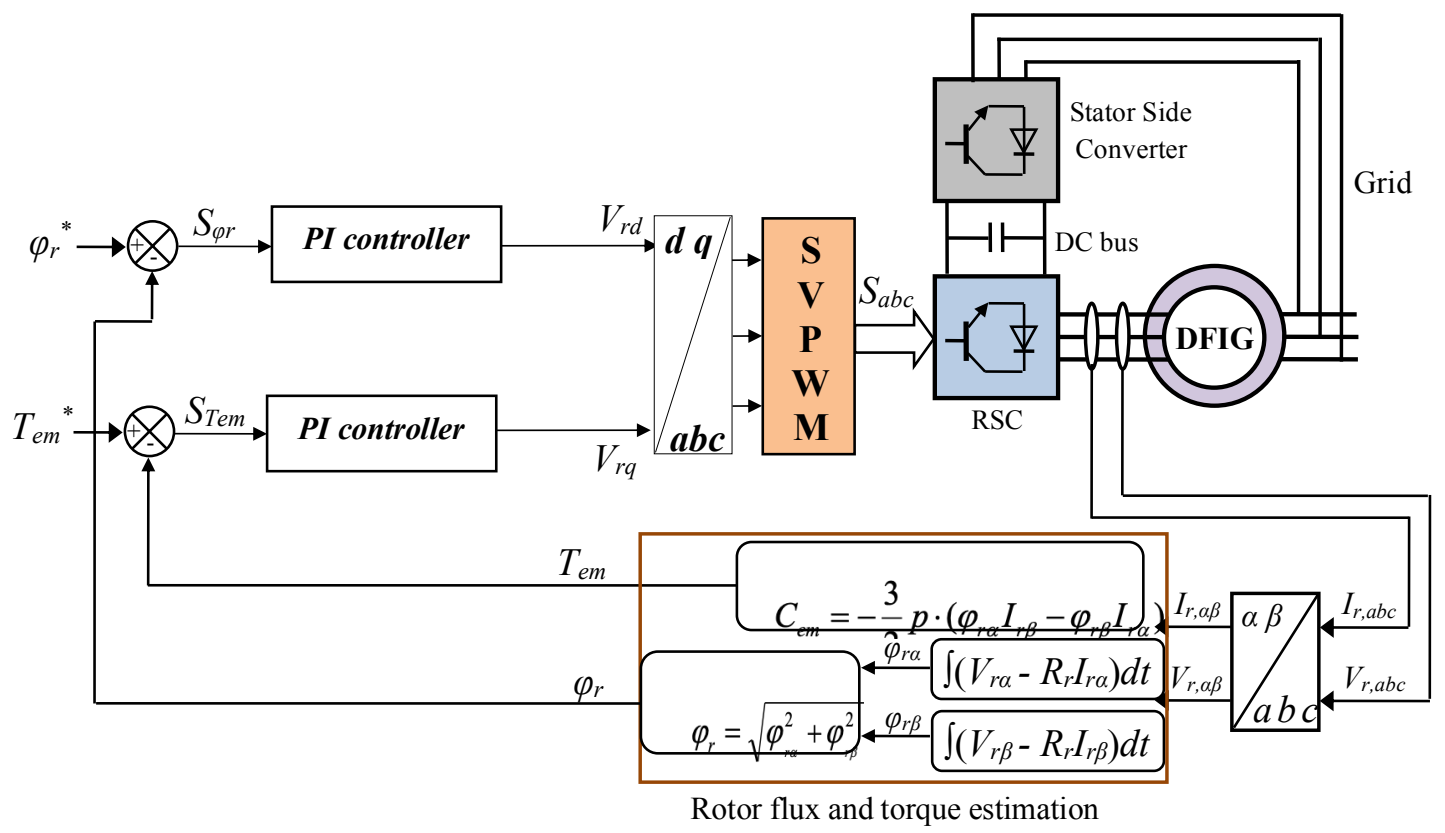

Figure 4. DTC with PI controllers.

The graphical representation of the control law of the STSMC controller is shown in Figure 5.

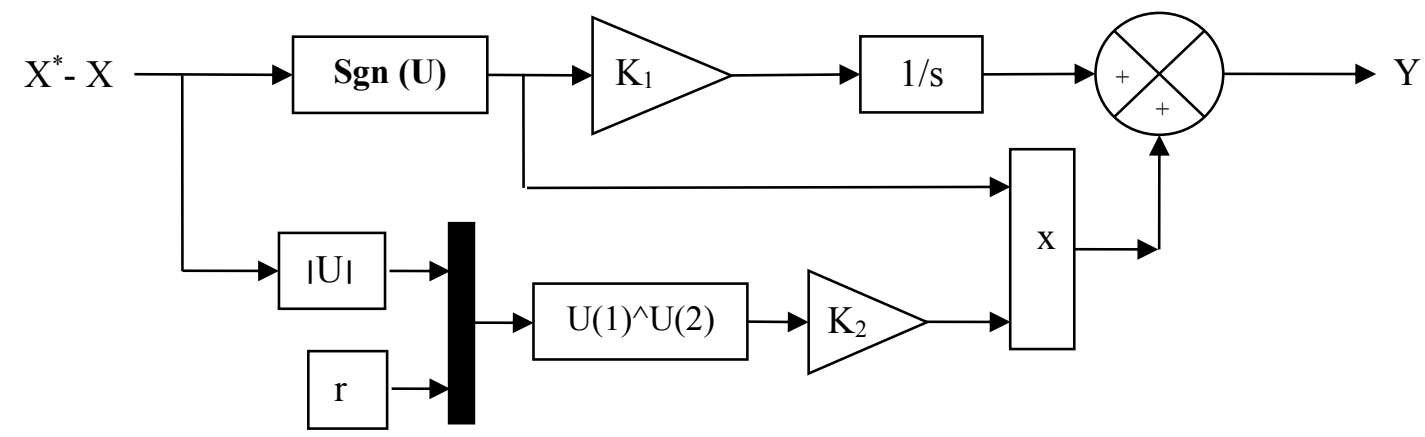

Figure 5. Graphical representation of the control law of the STSM algorithm.

$$
\frac{d x}{d t}=b(x, t) u+a(x, t) ; y=c(x, t)
$$

The procedure for determining the coefficients $\mathrm{Kp}$ and $\mathrm{Ki}$ of the super-twisting controllers is based on the analysis of equations for the nonlinear command system and the
Where $x$ is the state vector of the system; $a(x, t), b(x, t)$ and $\mathrm{c}(\mathrm{x}, \mathrm{t})$ are the vector functions; $\mathrm{u}$ is the vector of input command signals; $y$ is the vector of output control signals. 
The second time derivative of equations for the output signals has the matrix from presented as follows:

$$
\frac{d^{2} y}{d t^{2}}=B(x, t) \frac{d u}{d t}+A(x, t)
$$

The bounds of $\mathrm{B}(\mathrm{x}, \mathrm{t})$ and $\mathrm{A}(\mathrm{x}, \mathrm{t})$ of the second derivative of $y$ can be labelled as $A_{M}, A_{m}, B_{M}$ and $B_{m}$, where $B_{M}$ and $A_{M}$ are upper bounds and $A_{m}$ and $B_{m}$ are lower bounds. The $K_{1}$ and $\mathrm{K}_{2}$ are determined for all STSMC algorithms according to the equations presented as follows [31] :

$$
K_{1}>\frac{A_{M}}{B_{m}}, K_{2} \geq \frac{4 A_{M}}{B_{m}{ }^{2}} \cdot \frac{B_{M}\left(K_{1}+A_{M}\right)}{B_{m}\left(K_{1}-A_{M}\right)}
$$

In this work, the procedure for determining the coefficients $\mathrm{K}_{\mathrm{p}}$ and $\mathrm{K}_{\mathrm{i}}$ for the STSM of the DFIG powers has been presented. The same principle has been used to determine the values of the $K_{p}$ and $K_{i}$ for the super-twisting algorithm of the magnitude of the reactive/active power used in the DTC system with three-phase induction generator.

\section{ANFIS-STSM DTC strategy}

The DTC technique of a three-phase induction generator with the application of ANFIS-STSM algorithms is shown in Figure 6. In this method, the electromagnetic torque and rotor flux are controlled by the ANFIS-STSM algorithms. However, this proposed method reduced the torque ripples, flux ripples and THD of stator current for induction generator. This proposed control scheme is easy to implement and simple technique.

In the outer command loop of the induction generators electromagnetic torque and rotor flux, the reference value of the torque and flux is compared with the measured torque and flux. The switching function for torque and rotor flux can be specified as follows :
$\left\{\begin{array}{l}S_{T_{e}}=T_{e}^{*}-T_{e} \\ S_{\psi_{r}}=\psi_{r}^{*}-\psi_{r}\end{array}\right.$

The output signal for the electromagnetic torque controller is determined by the following system of equations :

$$
\left\{\begin{array}{c}
T_{e}^{*}=K_{P T e}\left|S_{T_{e}}\right|^{0.5} \operatorname{sgn}\left(S_{T e}\right)+T_{e 1}^{*} \\
\frac{d T_{e 1}^{*}}{d t}=K_{i T e} \operatorname{sgn}\left(S_{T e}\right)
\end{array}\right.
$$

Where Kpps and Kips are the coefficients of the proportional and integral part of the ANFIS-STSM electromagnetic torque regulator, respectively.

The procedure for determining the values of the coefficients Kpps and Kips is given in the following sections.

The second derivative of the switching function for the regulator of the induction generator electromagnetic torque can be defined as follows:

$\frac{d^{2} S_{T_{e}}}{d t^{2}}=\frac{d^{2} T_{e}^{*}}{d t^{2}}+\frac{d^{2} T_{e}}{d t^{2}}$

Equation (17) after the substitution of the converted torque equation (5) and the equation of the generator stator flux (17) and other algebraic manipulations takes the following from:

$\frac{d^{2} S_{T_{e}}}{d t^{2}}=\frac{d^{2} T_{e}^{*}}{d t^{2}}+\frac{d}{d t}\left(-\frac{3}{2} \cdot p \cdot \frac{L_{m} \cdot I_{q r}}{L_{s}} \psi_{d s}\right)$

The second derivate of the electromagnetic torque can be presented in the following from:

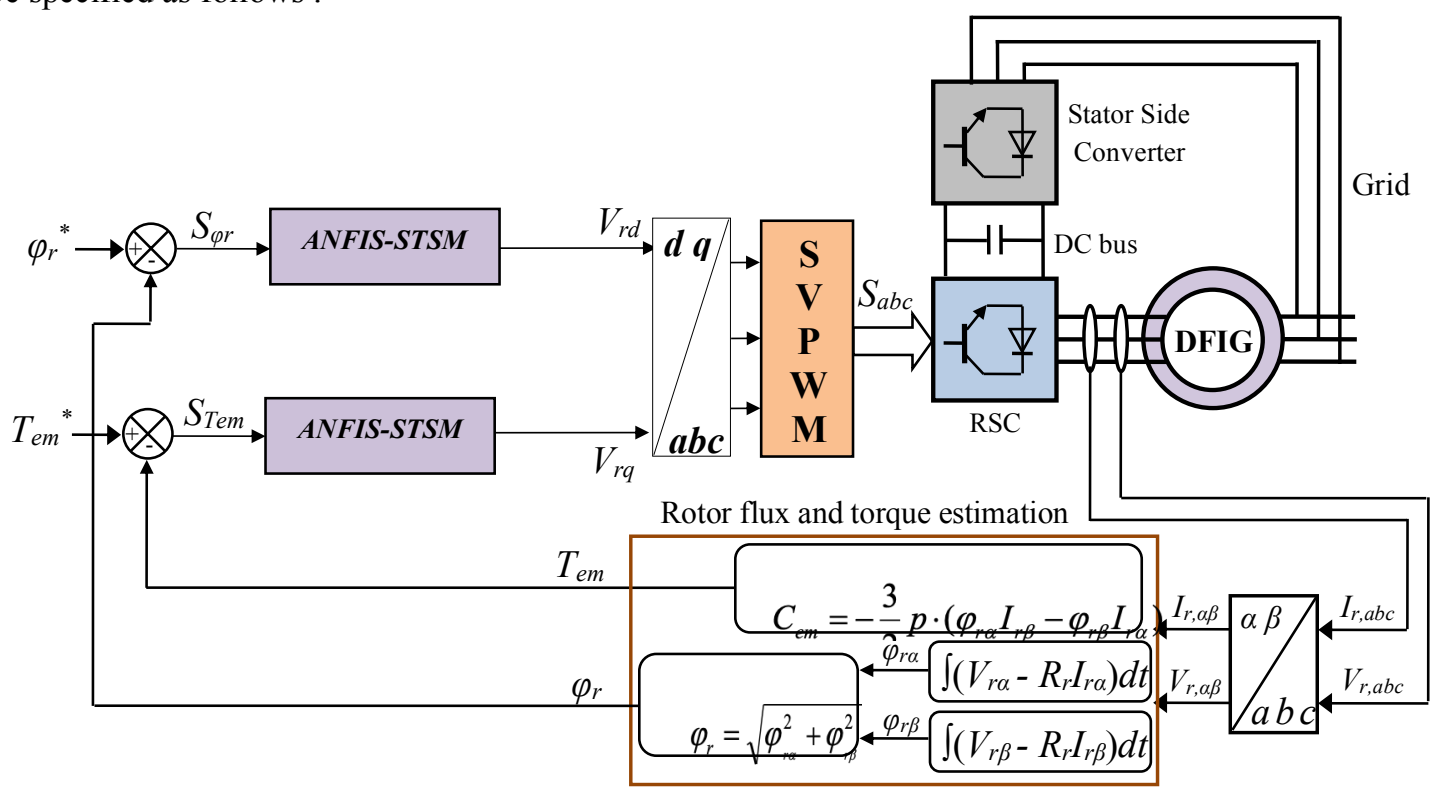

Figure 6. DTC system of DFIG with application of ANFIS-

STSM algorithms 
$\frac{d^{2} S_{P_{s}}}{d t^{2}}=\frac{d}{d t}\left(-\frac{3}{2} \cdot p \cdot \frac{L_{m} \cdot I_{q r}}{L_{s}} \psi_{d s}\right)$

Which gives the coefficients A and B:

$$
\begin{aligned}
& A=\frac{d}{d t} I_{q r} \cdot \psi_{d s} \\
& B=-\frac{3}{2} \frac{L_{m}}{L_{s}} \cdot p
\end{aligned}
$$

The coefficients B and A are used for the coefficients Kpp and Kip according to equation (16).

In the outer control loop of the flux, the reference value of the magnitude of the flux is compared with the estimated value. The switching function for flux controller can be specified as follows:

$$
S_{\psi_{r}}=\psi_{r}^{*}-\psi_{r}
$$

The output signal from the regulator of the magnitude of the rotor reactive power is determined by the following system of equations:

$$
\left\{\begin{array}{c}
\psi_{r}^{*}=K_{P_{\psi_{r}}}\left|S_{\psi_{r}}\right|^{0.5} \operatorname{sgn}\left(S_{\psi_{r}}\right)+\psi_{r 1}^{*} \\
\frac{d \psi_{r 1}^{*}}{d t}=K_{i{ }_{r}} \operatorname{sgn}\left(S_{\psi_{r}}\right)
\end{array}\right.
$$

Where $\mathrm{Kp}_{\psi}$ and $\mathrm{Ki}_{\psi}$ are the coefficients of the proportional and integral parts of the STSM rotor flux regulator, respectively.

In the analyzed DTC system with super-twisting algorithms, the two inner command loops have also been applied: the command loop for the Te and $\psi_{\mathrm{r}}$.
In the inner control loop of the $\psi_{\mathrm{r}}$, the reference value of this component is compared with the measured transformed value. On the other hand, The block diagram of the ANFISSTSM algorithm is shown in Figure 7.

An ANFIS algorithm is an FLC scheme that employs a learning procedure resulting from the NN principle to find out its parameters (fuzzy sets and rules) by dealing with data examples. By mixing both NN and FL command, it is possible to achieve the advantages of both the commands in single implementation [32]. The ANFIS based STSM algorithm is given in Figure 8. The ANFIS rules for the proposed algorithm are given in Table 1. On the other hand, The training used is that of the algorithm, Gradiant descent with momentum \& Adaptive LR. The convergence of the network in summer obtained by using the value of the parameters grouped in Table 2.

Table 1. ANFIS ruls

\begin{tabular}{clllllll}
\hline $\mathbf{e}$ & NB & NM & NS & EZ & PS & PM & PB \\
$\Delta \mathbf{e}$ & & & & & & & \\
\hline NB & NB & NB & NB & NB & NM & NS & EZ \\
NM & NB & NB & NB & NM & NS & EZ & PS \\
NS & NB & NB & NM & NS & EZ & PS & PM \\
EZ & NB & NM & NS & EZ & PS & PM & PB \\
PS & NM & NS & EZ & PS & PM & PB & PB \\
PM & NS & EZ & PS & PM & PB & PB & PB \\
PB & EZ & PS & PM & PB & PB & PB & PB \\
\hline
\end{tabular}

Figure 9 shows the $\mathrm{NN}$ training performance of the $\mathrm{NN}$ regulator for ANFIS-STSM algorithms. On the other hand, the Figure 10 show the Gradiant, validation checks and

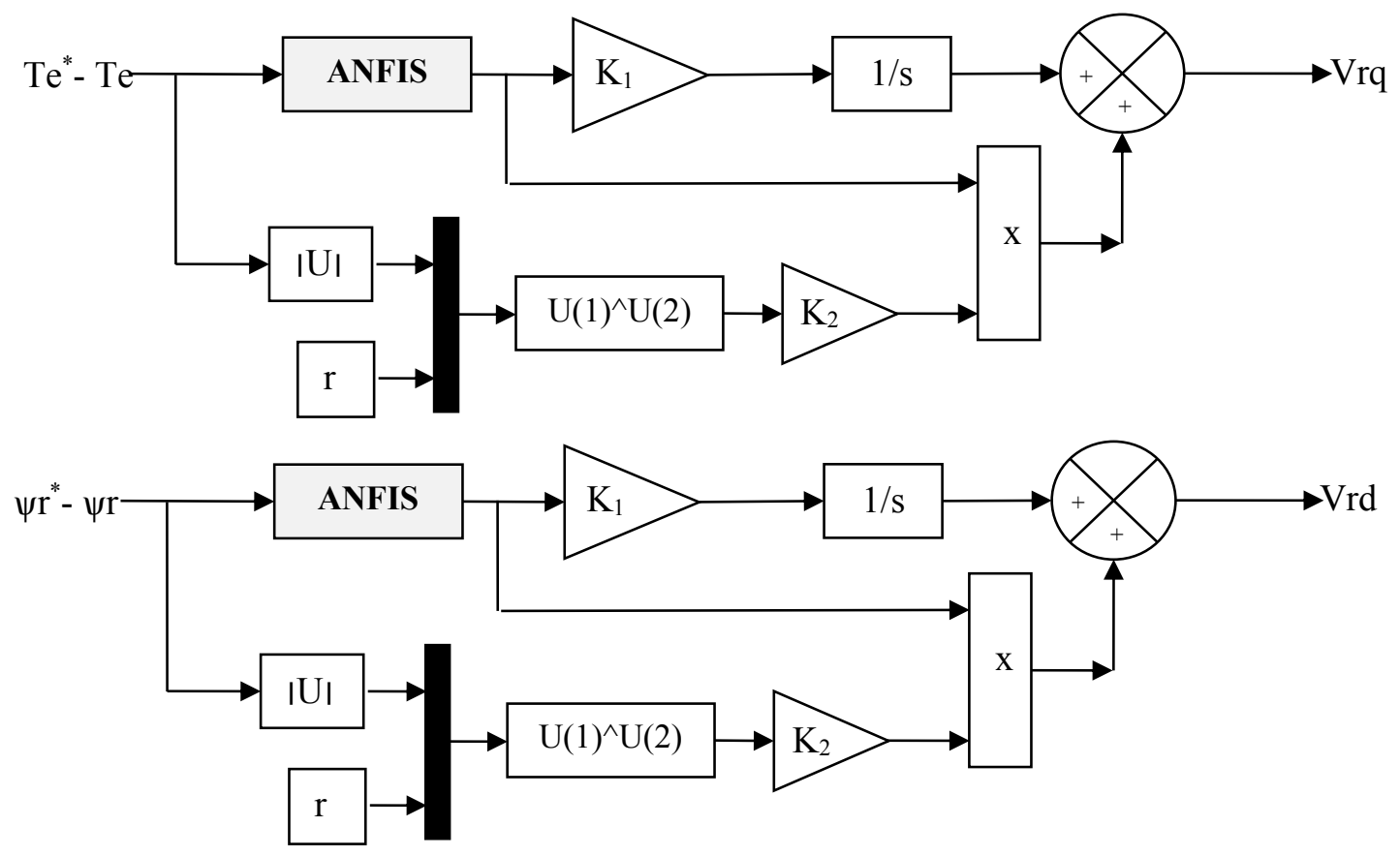

Figure 7. Block diagram of the ANFIS-STSM algorithms. 
Learning Rate performances of the ANFIS-STSM algorithms (torque and rotor flux).

Table 2. Parameters of the ALR for ANFIS regulator.

\begin{tabular}{|l|c|}
\hline Parameters of the ALR & Values \\
\hline Number of hidden layer & 12 \\
\hline Training & $\begin{array}{l}\text { Gradiant descent with momentum } \\
\text { \& Adaptive LR (traingdx) }\end{array}$ \\
\hline TrainParam.Lr & 0.05 \\
\hline TrainParam.show & 50 \\
\hline Performance & Mean squared error (mse) \\
\hline TrainParam.eposh & 1000 \\
\hline $\begin{array}{l}\text { Coeff of acceleration of } \\
\text { convergence (mc) }\end{array}$ & 0.8 \\
\hline derivative & Defaut (defaultderiv) \\
\hline TrainParam.goal & 0 \\
\hline TrainParam.mu & 0.8 \\
\hline Functions of activation & Tensing, Purling, traingdx \\
\hline
\end{tabular}

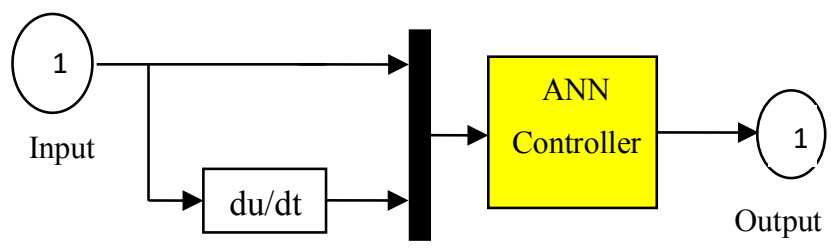

Figure 8. Block diagram of the ANFIS regulator.

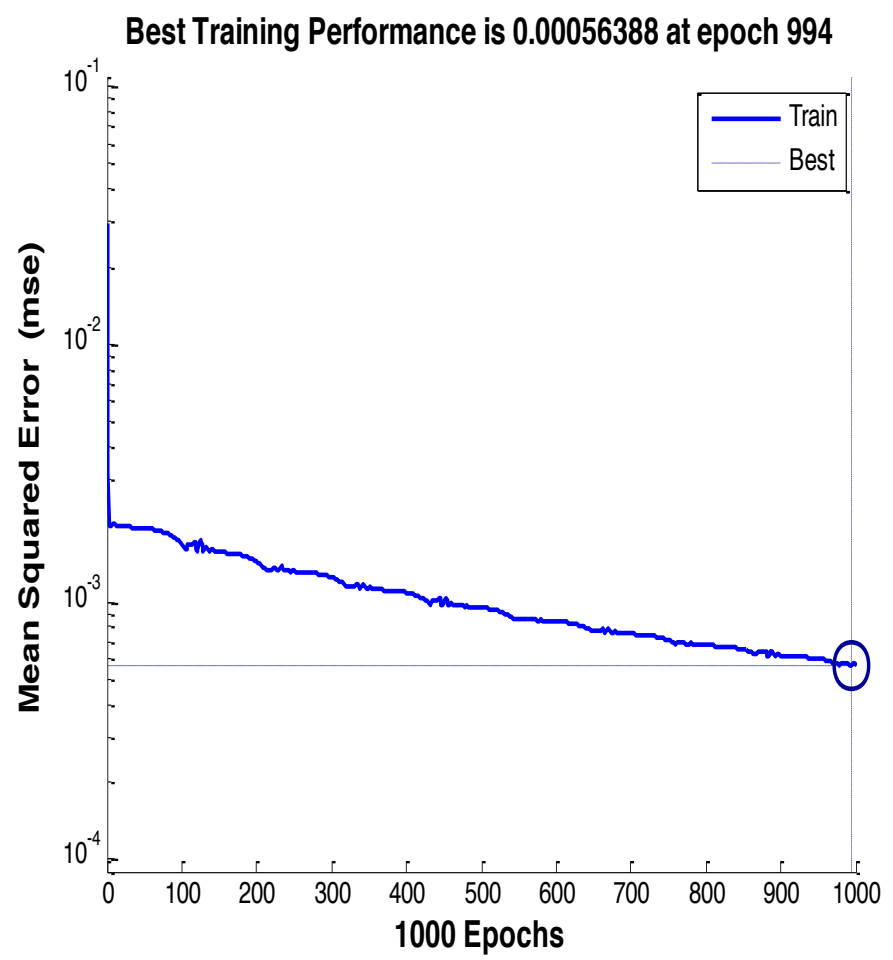

a) Rotor flux

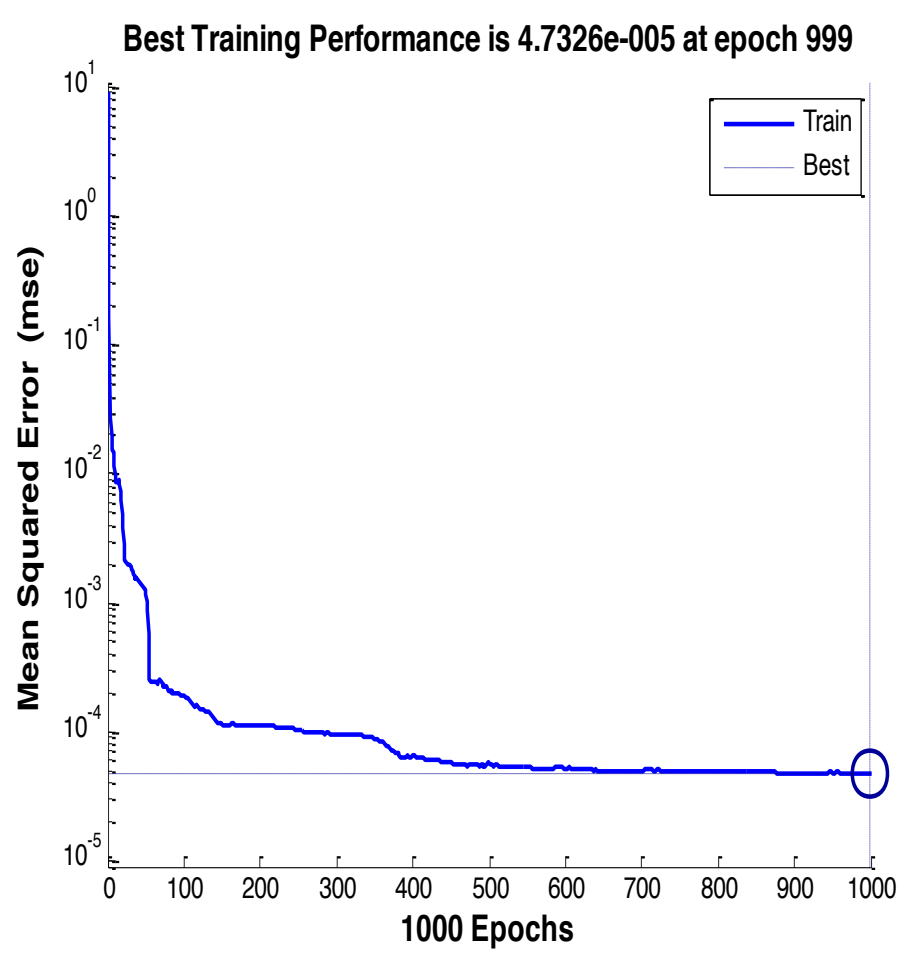

b) Torque

Figure 9. Training performance of NN regulator.

Gradient $=0.020032$, at epoch 1000

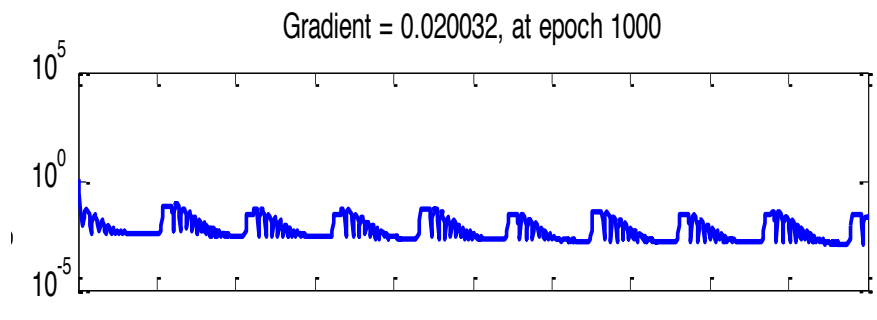

Validation Checks $=0$, at epoch 1000

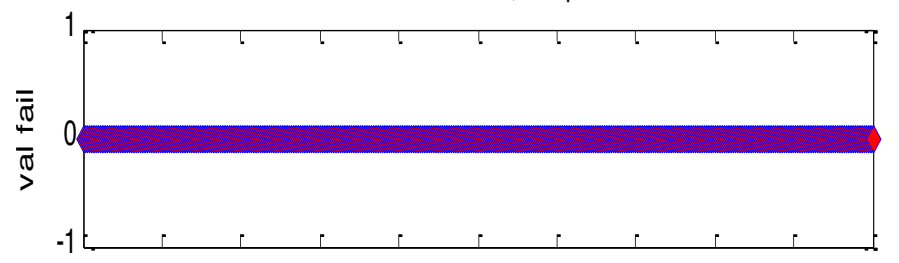

Learning Rate $=0.051614$, at epoch 1000

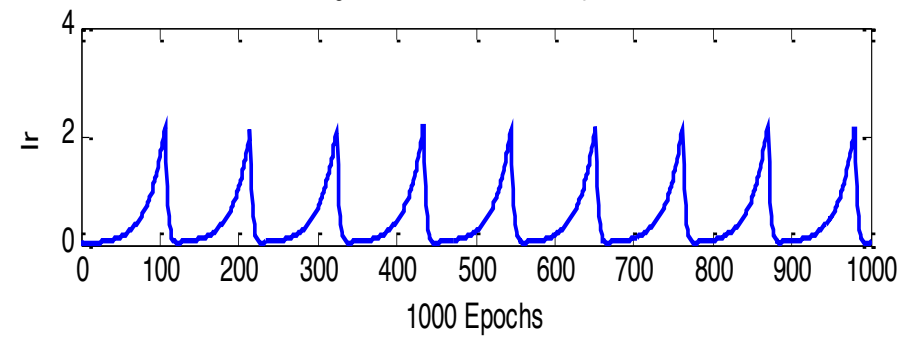

a) Rotor Flux 


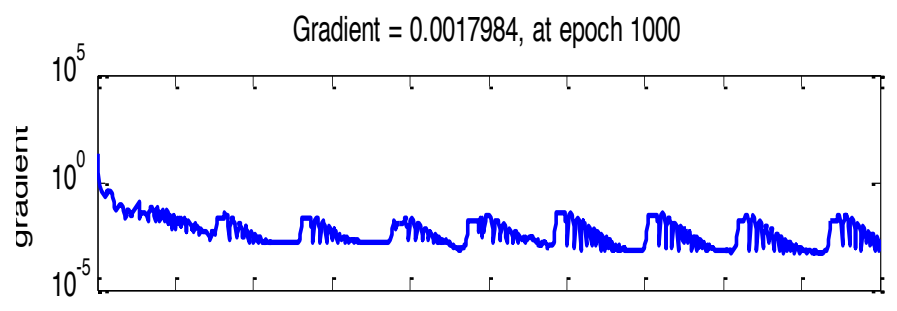

Validation Checks $=0$, at epoch 1000

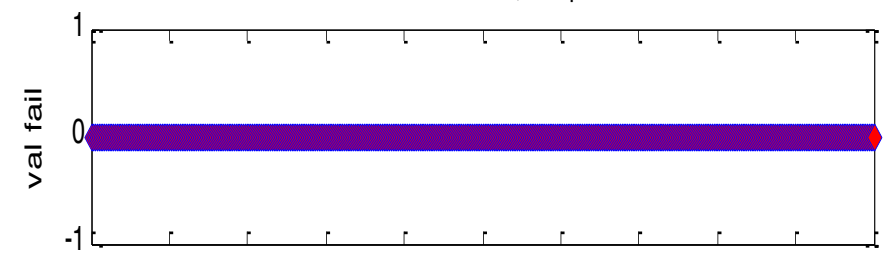

Learning Rate $=0.016804$, at epoch 1000

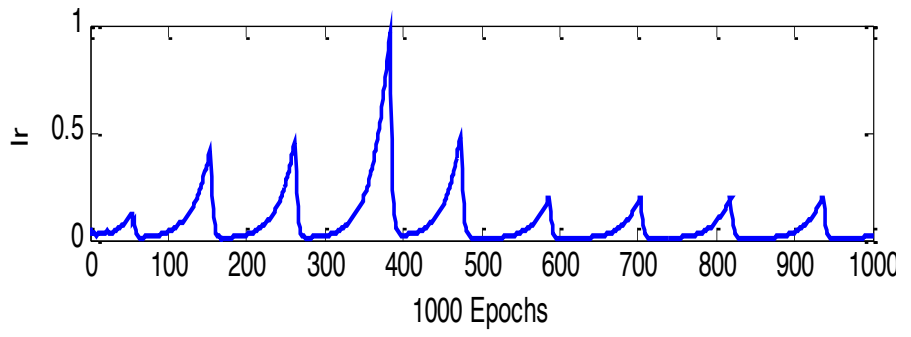

b) Torque

Figure 10. Gradiant, Validation Checks and Learning Rate performances

\section{Simulation studies of ANFIS-STSM DTC method}

The simulation studies of the considered strategy method have been carried out using the especially designed. Simulation studies were carried out for the three-phase induction generator with the following data and parameters : $\mathrm{Pn}=1 \mathrm{MW}$, stator voltage : $380 / 696 \mathrm{~V}$, two poles, stator voltage frequency : $50 \mathrm{~Hz} ; R_{s}=0.012 \Omega, L_{s}=0.0137 \mathrm{H}, R_{r}=$ $0.021 \Omega, L_{r}=0.0136 \mathrm{H}, L_{m}=0.0135 \mathrm{H}, J=1000 \mathrm{~kg} . \mathrm{m}^{2}$ and $f_{r}$ $=0.0024 \mathrm{Nm} / \mathrm{s}[33,34]$.

\section{A. Reference tracking test (RTT)}

Figures 11-12 show the stator current THD of DFIG for the DTC-ANFIS-STSM method and DTC-PI respectively. It can be clearly observed that the THD is minimized for the DTCANFIS-STSM control scheme (THD $=0.32 \%$ ) when compared to DTC-PI $($ THD $=0.65 \%)$. Figures $13-15$ show the obtained simulation results. For the DTC-ANFIS-STSM and DTC-PI method, the rotor flux and electromagnetic torque track almost perfectly their reference values $\left(T_{e-r e f}\right.$ and $\left.\psi_{s-r e f}\right)$. Moreover, the DTC-ANFIS-STSM method minimized the stator current, rotor flux, and torque ripples compared to the DTC-PI (See Figs 16-18).
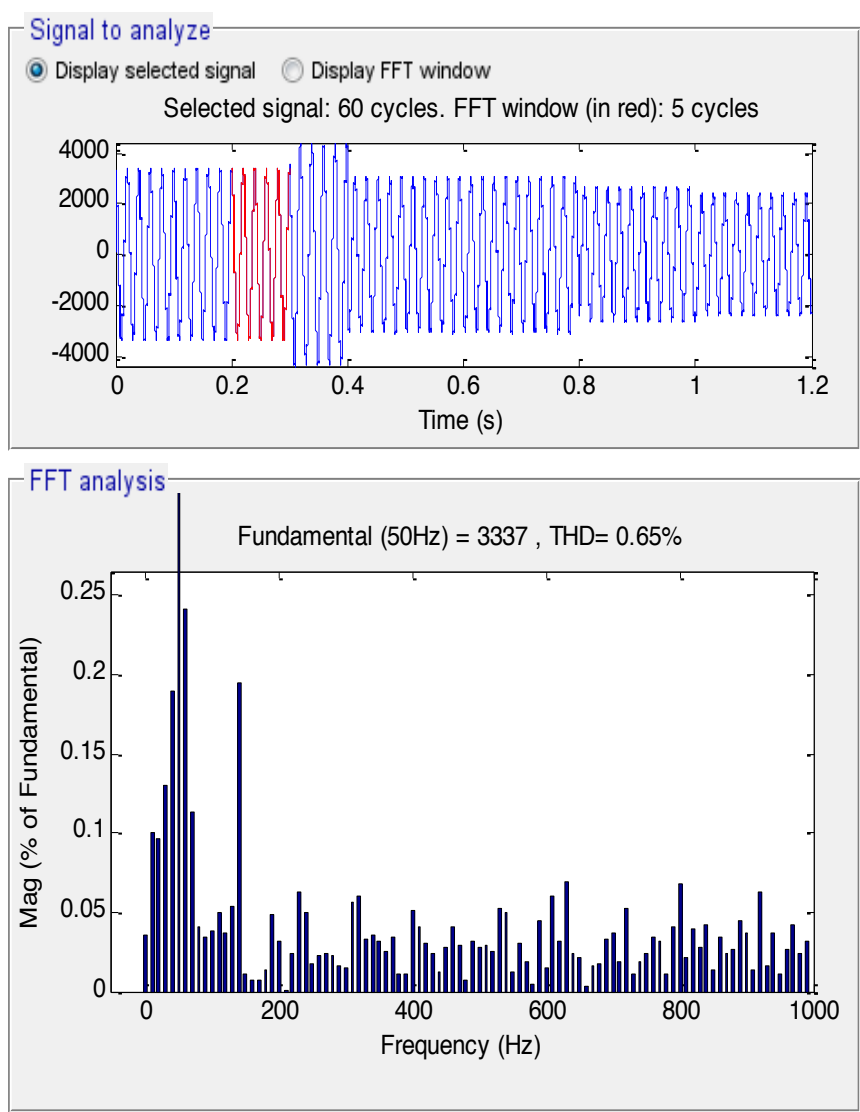

Figure 11. Harmonic distortion (DTC-PI).
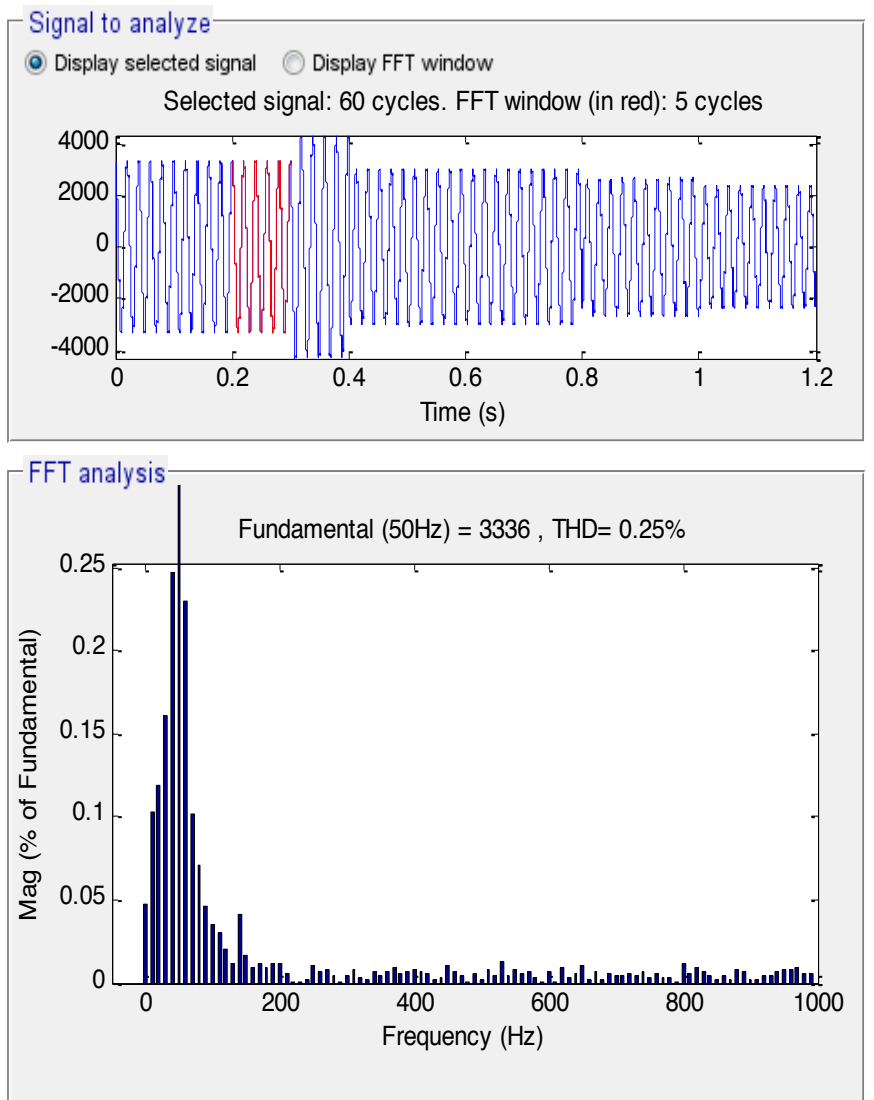

Figure 12. Harmonic distortion (DTC-ANFIS-STSMC). 


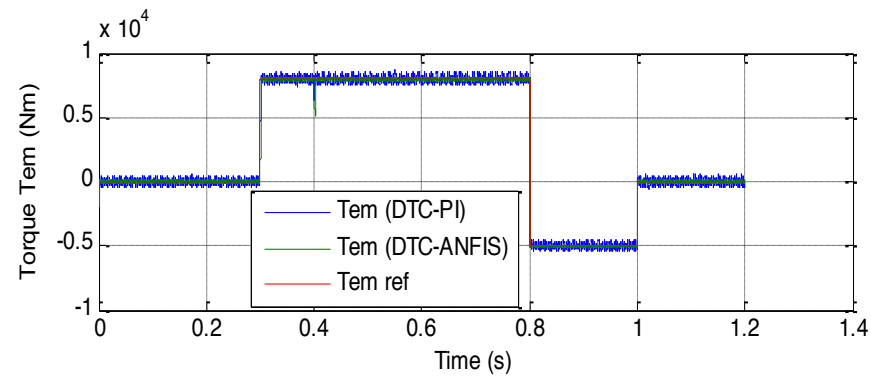

Figure 13. Torque

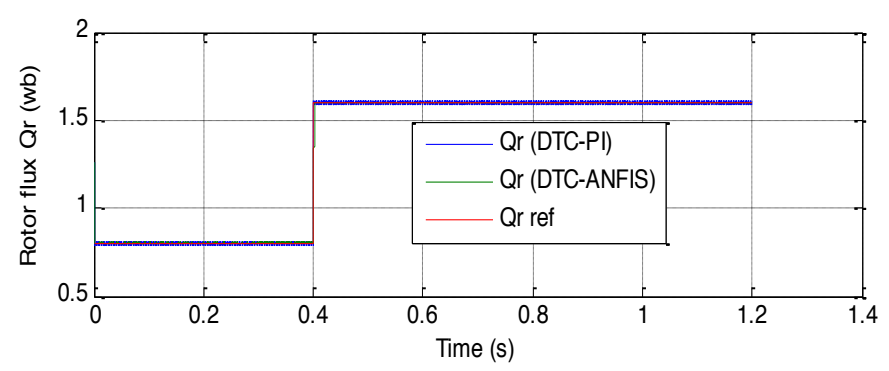

Figure 14. Rotor flux

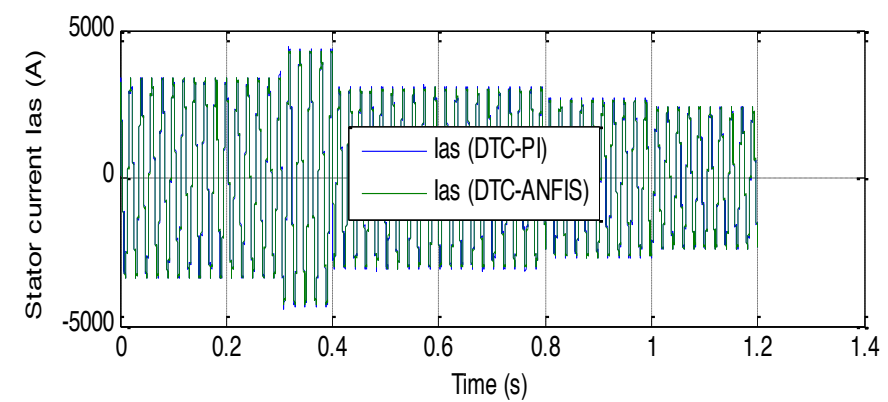

Figure 15. Stator current.

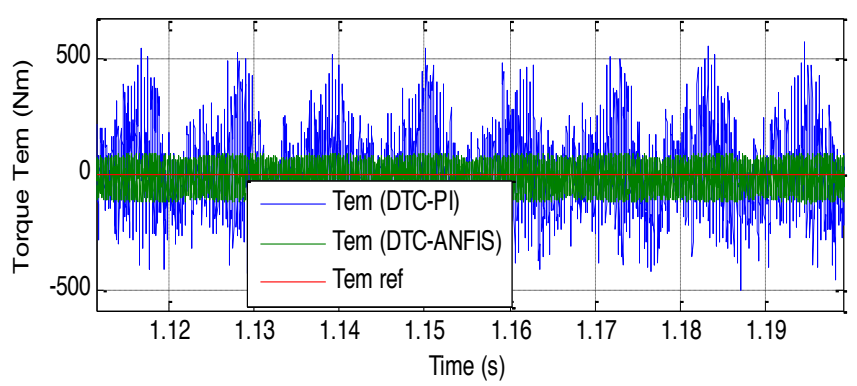

Figure 16. Zoom in the torque

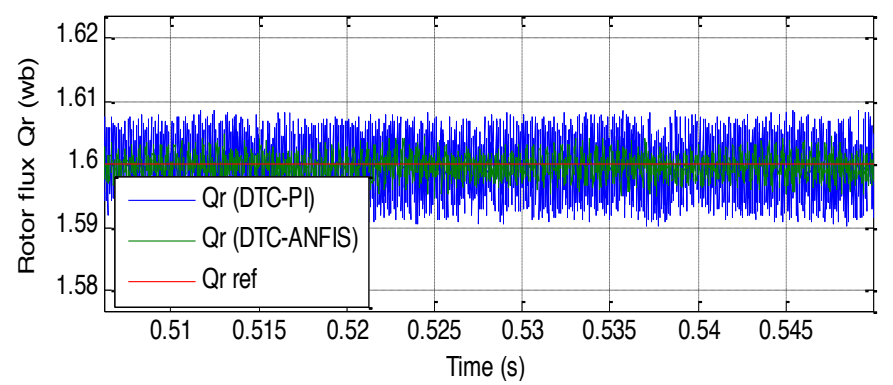

Figure 17. Zoom in the rotor flux.

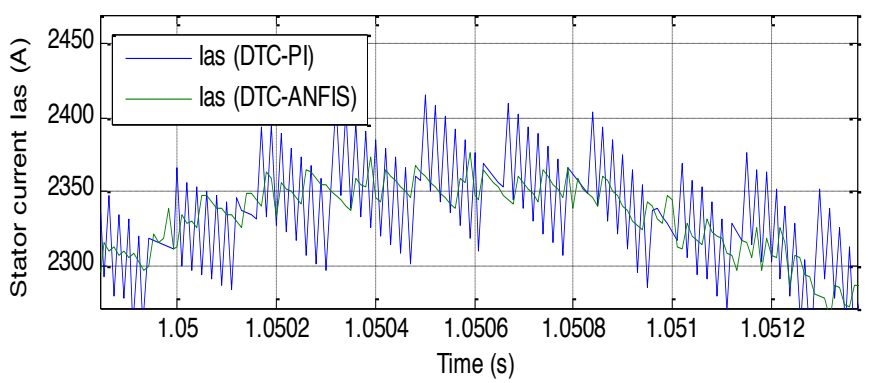

Figure 18. Zoom in the stator current.

\section{B.Robustness test (RT)}

In this test, the nominal values of $R_{r}$ and $R_{s}$ are multiplied by 2. Simulation results are presented in Figures 19-23. As it's shown by these figures, these variations present an apparent effect on stator current, rotor flux and torque such as the effect appears more significant for the DTC-PI method compared to DTC-ANFIS-STSM (See Figures 24-26).

The THD value of stator current in the DTC-ANFIS-STSMC method has been minimized significantly (See Figures 2627). Table 3 shows the comparative analysis of THD values. Thus it can be concluded that the proposed DTC with ANFIS-STSMC algorithms is more robust than the conventional DTC strategy.

Table 3. Comparative analysis of THD value
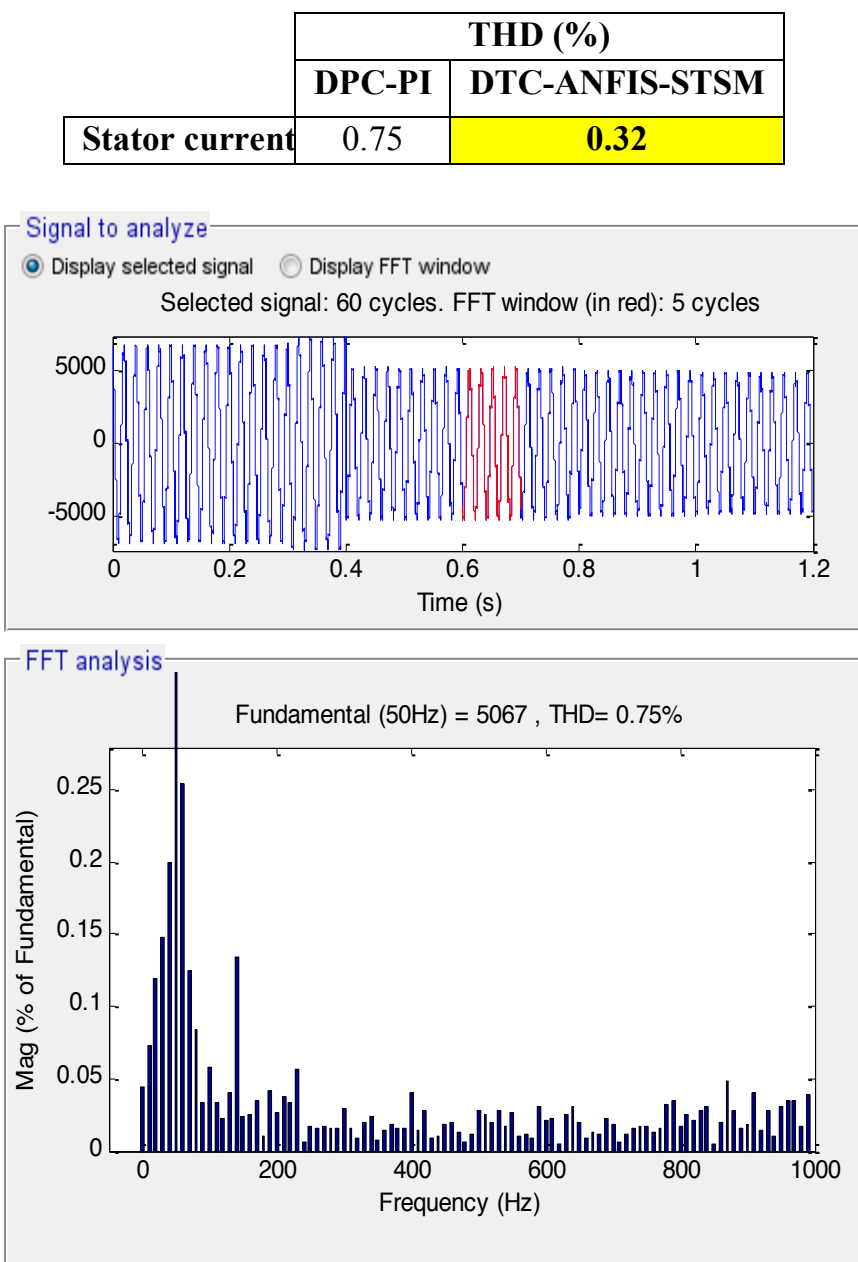

Figure 19. Harmonic distortion (DTC-PI). 

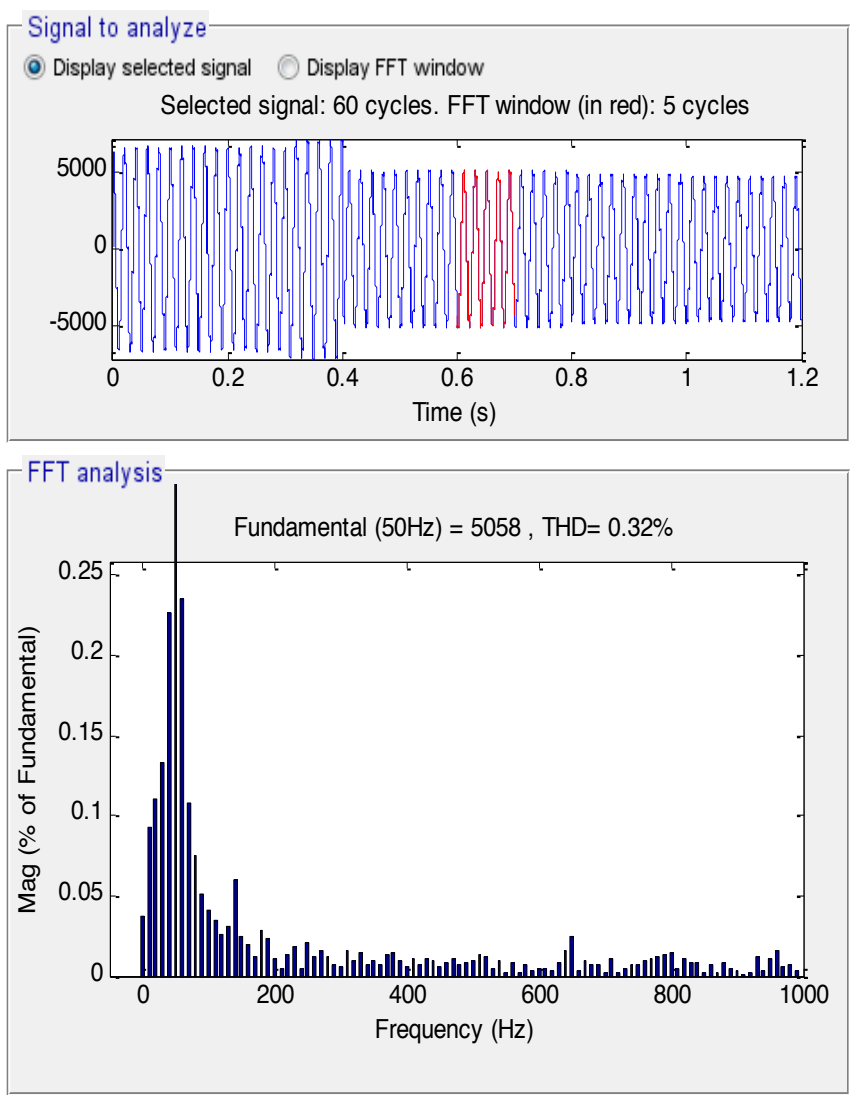

Figure 20. Harmonic distortion (DTC-ANFIS-STSM).

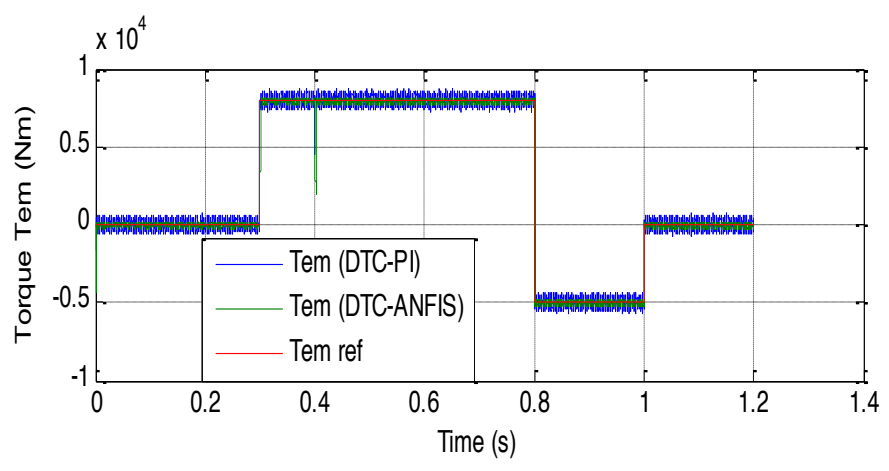

Figure 21. Torque.

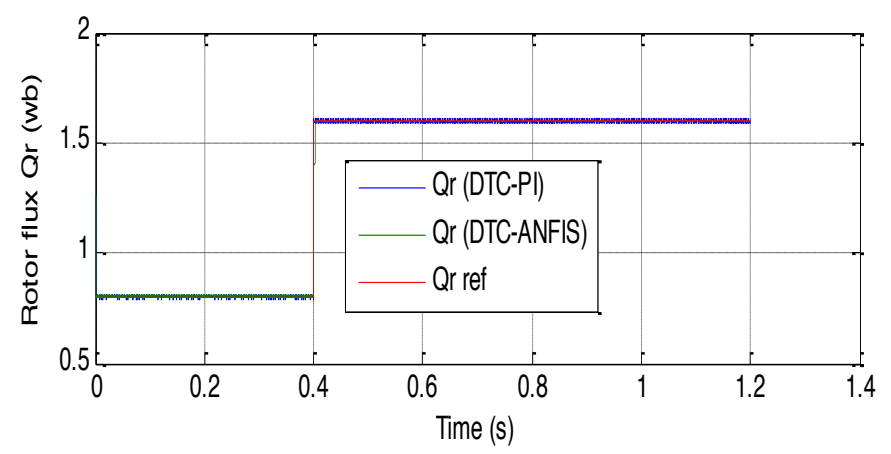

Figure 22. Rotor flux.

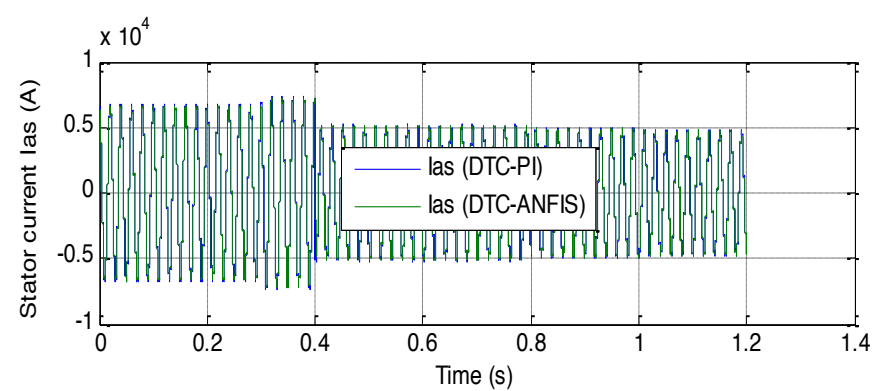

Figure 23. Stator current.

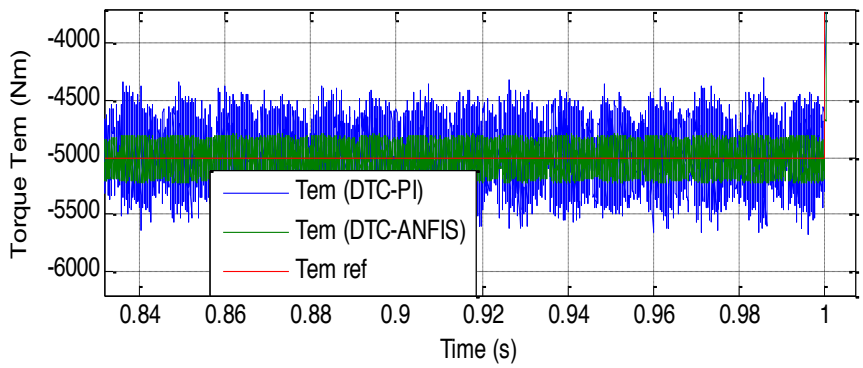

Figure 24. Zoom in the torque

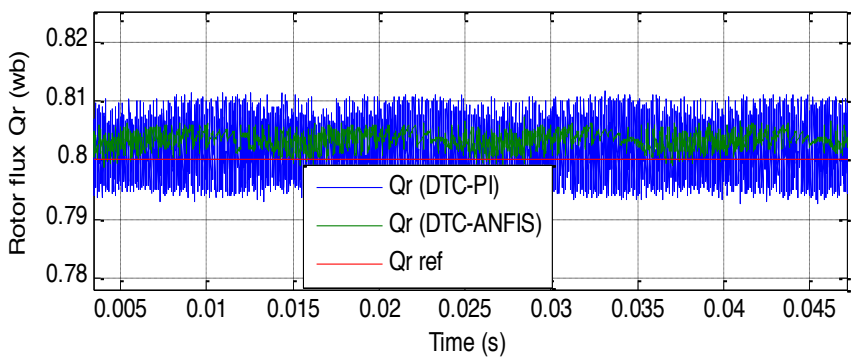

Figure 25. Zoom in the rotor flux.

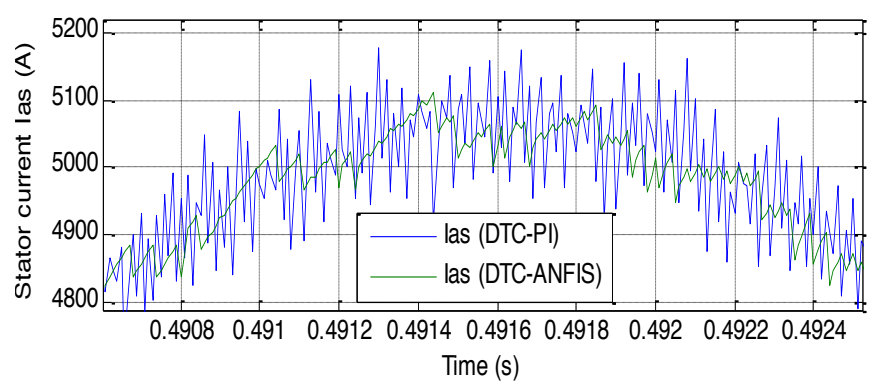

Figure 26. Zoom in the stator current.

\section{Conclusions}

The main objective of this work was to develop an improved DTC strategy of a DFIG integrated into a WES. The basic idea was to use ANFIS-STSM hybrid controllers associated with a DTC-PI method. Numerical simulations by MATLAB / SIMULINK have been developed to test the performances provided by the techniques used. The results of simulation 
obtained show well the superiority of the proposed technique (DTC-ANFIS-STSM) compared to the DTC-PI especially in the attenuation of the fluctuations of the flux and electromagnetic torque supplied and the robustness against parametric variations.

\section{References}

[1] H. Benbouhenni, "Fuzzy second order sliding mode controller based on three-level fuzzy space vector modulation of a DFIG for wind energy conversion systems", Majlesi Journal of Mechatronic Systems, Vol. 7, No. 3, pp. 17-26, 2018.

[2] H. Benbouhenni, "Neuro-sconde order sliding mode field oriented control for DFIG based wind turbine", International Journal of Smart Grid, Vol. 2, No. 4, pp. 209-217, 2018.

[3] H. Benbouhenni, "Comparative study between direct vector control and fuzzy sliding mode controller in three-level space vector modulation inverter of reactive and active power command of DFIG-based wind turbine systems", International Journal of Smart Grid, Vol. 2, No. 4, pp. 188-196, 2018.

[4] Z. Boudjema, A. Meroufel, A. Amari, "Robust control of a doubly fed induction generator (DFIG) fed by a direct AC-AC converter", Przegląd Elektrotechniczny, Vol. 11, pp. 213-221, 2012.

[5] Y. Bekakra, D. Ben Attous, "Comparison study between SVM and PWM inverter in sliding mode control of active and reactive power control of a DFIG for variable speed wind energy", International Journal of Renewable Energy Research, Vol. 2, No. 3, pp. 471-476, 2012.

[6] A. Yahdou, B. Hemici, Z. Boudjema, "Second order sliding mode control of a dual-rotor wind turbine system by employing a matrix converter", Journal of Electrical Engineering, Vol. 16, No. 4, pp. 1-11, 2016.

[7] N. Khemiri, A. Khedher, M. F. Mimouni, "Wind energy conversion system using DFIG controlled by backstepping and sliding mode strategies", International Journal of Renewable Energy Research, Vol. 2, No. 3, pp. 422-435, 2012.

[8] H. Benbouhenni, "Application of five-level NPC inverter in DPC-ANN of doubly fed induction generator for wind power generation systems", International Journal of Smart Grid, Vol. 3, No. 3, pp. 128-137, 2019.

[9] H. Benbouhenni, Z. Boudjema, A. Belaidi, "Sensorless twelve sectors implementation of neural DPC controlled DFIG for reactive and active powers ripples reduction", Majlesi Journal of Energy Management, Vol. 7, No. 2, 2018.

[10]H. Benbouhenni, "Torque ripple reduction of DTC DFIG drive using neural PI regulators", Majlesi Journal of Energy Management, Vol. 8, No. 2, pp. 21-26, 2019.
[11]H. Benbouhenni, "Sliding mode with neural network regulateur for DFIG using two-level NPWM strategy", Iranian Journal of Electrical \& Electronic Engineering, Vol. 15, No. 3, pp. 411-419, 2019.

[12]H. Benbouhenni, "Comparative study between PWM and SVPWM technique for a DFIG-based wind turbine system controlled by fuzzy sliding mode", Majlesi Journal of Energy Management, Vol. 7, No. 4, 2018.

[13]H. Benbouhenni, “ANFIS-sliding mode control of a DFIG supplied by a two-level SVPWM technique for wind energy conversion system", International Journal of Applied Power Engineering (IJAPE), Vol. 8, No. 1, pp. 36-47, 2020.

[14]H. Benbouhenni, Z. Boudjema, A. Belaidi, "Neurosecond order sliding mode control of a DFIG supplied by a two-level NSVM inverter for wind turbine system", Iranian Journal of Electrical \& Electronic Engineering, Vol. 14, No. 4, pp.362-373, 2018.

[15]H. Benbouhenni, "Fuzzy second order sliding mode controller based on three-level fuzzy space vector modulation of a DFIG for wind energy conversion systems," Majlesi Journal of Mechatronic Systems, Vol. 7, No. 3, pp.17-26, 2018.

[16]H. Benbouhenni, "Second order sliding mode with ANFIS controllers for DFIG using seven-level NSVPWM technique", Majlesi Journal of Energy Management, Vol. 8, No. 1, pp. 29-39, 2019.

[17] H. Benbouhenni, Z. Boudjema, A. Belaidi, "Indirect vector control of a DFIG supplied by a two-level FSVM inverter for wind turbine system", Majlesi Journal of Electrical Engineering, Vol. 13, No. 1, 2019.

[18] Z. Boudjema, A. Meroufel, E. Bounadja, Y. Djerriri, "Nonlinear control of a doubly fed induction generator supplied by a matrix converter for wind energy conversion systems", Journal of Electrical Engineering, Vol. 13, No. 4, pp. 269-276, 2013.

[19] H. Benbouhenni, "Neuro-sconde order sliding mode field oriented control for DFIG based wind turbine", International Journal of Smart Grid, Vol. 2, No. 4, pp. 209-217, 2018.

[20]H. Benbouhenni, "A novel switching tables of twelve sectors DTC for induction machine drive using artificial neural networks", Automation, Control and Intelligent Systems, Vol. 7, No. 1, pp. 1-8, 2019.

[21] Z. Boudjema, R. Taleb, Y. Djerriri, A. Yahdou, "A novel direct torque control using second order continuous sliding mode of a doubly fed induction generator for a wind energy conversion system", Turkish Journal of Electrical Engineering \& Computer Sciences, Vol. 25, pp. 965-975, 2017.

[22] Z. Boudjema, A. Meroufel, Y. Djerriri, E. Bounadja, "Fuzzy sliding mode control of a doubly fed induction 
generator for wind energy conversion", Carpathian Journal of Electronic and Computer Engineering, Vol. 6, No. 2, pp. 7-14, 2013.

[23] H. Benbouhenni, Z. Boudjema, "Two-level DTC based on ANN controller of DFIG using 7-level hysteresis command to reduce flux ripple comparing with traditional command”, IEEE Xplore, 2019.

[24] H. Benbouhenni, Z. Boudjema, A. Belaidi, "Higher control scheme using neural second order sliding mode and ANFIS-SVM strategy for a DFIG-based wind turbine", International Journal of Advances in Telecommunications, Electrotechnics, Signals and Systems, Vol. 8, No. 2, pp. 17-28, 2019.

[25] H. Benbouhenni, Z. Boudjema, A. Belaidi, "Direct vector command based on three-level NSVM of a doubly fed induction generator for wind energy conversion”, IEEE Xplore, 2019.

[26] H. Benbouhenni, "Comparison study between SVPWM and FSVPWM strategy in fuzzy second order sliding mode control of a DFIG-based wind turbine", Carpathian Journal of Electronic and Computer Engineering, Vol. 12, No. 2, pp. 1-10, 2019.

[27] H. Benbouhenni, "A direct power control of the doubly fed induction generator based on the three-level NSVPWM technique", International Journal of Smart Grid, Vol. 3, No. 4, 2019.

[28] H. Benbouhenni, "Stator current and rotor flux ripples reduction of DTC DFIG drive using FSTSMC algorithm", International Journal of Smart Grid, Vol. 3, No. 4, 2019.
[29] S. Tayebi-Haghighi, F. Piltan, J. M. Kim, "Robust Composite High-Order Super-Twisting Sliding Mode Control of Robot Manipulators", Robotics, Vol. 7, No. 1, 2018.

[30] J. Listwan, “Application of Super-Twisting Sliding Mode Controllers in Direct Field-Oriented Control System of Six-Phase Induction Motor: Experimental Studies", Power Electronics and Drives, Vol. 38, No. 1, 2018.

[31] I. Yaichi, A. Semmah, P. Wira, Y. Djeriri, "Supertwisting sliding mode control of a doubly-fed induction generator based on the svm strategy", Periodica Polytechnica Electrical Engineering and Computer Science, Vol. 63, No. 3, pp. 178-190, 2019.

[32] V. K. Arun Shankar, S. Umashankar, P. Sanjeevikumar, S. Paramasivam, "Adaptive neuro-inference system (ANFIS) based direct torque control of PMSM driven centrifugal pump", International Journal of Renewable Energy Research, Vol. 7, No. 3, pp.1437-1477, 2017.

[33] H. Benbouhenni, "A comparative study between NSMC and NSOSMC strategy for a DFIG integrated into wind energy system", Carpathian Journal of Electronic and Computer Engineering, Vol. 12, No. 1, pp. 1-8, 2019.

[34] H. Benbouhenni, Z. Boudjema, A. Belaidi, "Intelligent SVM technique of a multi-level inverter for a DFIGbased wind turbine system", Int. J. Digital Signals and Smart Systems, Vol. 3, Nos. 1/2/3, pp. 4-19, 2019. 